\title{
A predictive model for the utilization of curative ambulatory health services in Mexico
}

\author{
Atanacio Valencia-Mendoza, MCES, (I) Stefano M Bertozzi, MD, PhD. (1,2) $^{2}$
}

\begin{abstract}
Valencia-Mendoza A, Bertozzi SM.
A predictive model for the utilization of curative ambulatory health services in Mexico. Salud Publica Mex 2008;50:397-407.
\end{abstract}

\begin{abstract}
Objectives. To estimate the degree to which individual and household variables jointly predict utilization of curative ambulatory services in Mexico for four types of health providers. Material and Methods. Patient choice of provider (selfcare, Ministry of Health, social security, or private provider) when they become ill is modeled using a nested multinomial logit model that uses household and individual variables as predictors. The data are from the Mexican National Health Survey conducted in 2000. Results. Being a social security beneficiary is one of the most important predictors of utilization.A strong positive relationship between socio-economic status (SES) and demand for services was also found, with the strongest relationship being for private providers, followed by social security. Utilization of Ministry of Health (MoH) services was negatively associated with household SES. Conclusions. Expansion of health insurance coverage should significantly reduce health inequalities due to reduced care-seeking by non-beneficiaries.
\end{abstract}

Keywords: utilization; health services; Mexico

\section{Valencia-Mendoza A, Bertozzi SM.}

Un modelo predictivo de la utilización

de servicios de salud ambulatorios curativos en México.

Salud Publica Mex 2008;50:397-407.

\section{Resumen}

Objetivo. Estimar el grado en el cual variables individuales, del hogar y comunitarias predicen la utilización de servicios ambulatorios curativos en México. Material y métodos. Ante un problema de salud los individuos pueden elegir utilizar servicios médicos, servicios de la Secretaría de Salud (SSa), de la Seguridad Social (SS) o Privados (SP). Esta elección es modelada con datos de la ENSA 2000 mediante un modelo logístico multinomial anidado. Resultados. El predictor más importante de la utilización de servicios de salud fue la derechohabiencia a la SS. Se encontró una fuerte relación positiva entre estatus socioeconómico (ESE) y la utilización de servicios de salud. Dicha relación es mayor para la utilización de SP, seguida de la SS. Se encontró una relación negativa entre el ESE y la utilización de servicios de la SSa. Conclusión. Expandir la cobertura de aseguramiento reduciría significativamente las inequidades en salud debidas a la baja utilización de servicios de salud por los no beneficiarios.

Palabras clave: utilización; servicios de salud; México

(I) Centro de Investigación en Evaluación y Encuestas, Instituto Nacional de Salud Pública. México.

(2) Centro de Investigación y Docencia Económicas Haas School of Business. UC Berkeley. EUA.

Received on: October 19,2007 • Accepted on: April II, 2008.

Address reprint requests to:Atanacio Valencia-Mendoza. Centro de Investigación en Evaluación y Encuestas, Instituto Nacional de Salud Pública. Av. Universidad 655, col. Santa María Ahuacatitlán. 62508 Cuernavaca, Morelos, México. e-mail: avalencia@correo.insp.mx 
$\mathrm{T}_{\mathrm{i}, \mathrm{s}}$ he health status of a population is one of the most important factors in the process of economic development for at least two reasons. In the first place, health as an indicator of economic development shows the degree to which a country successfully provides for the basic needs of its citizens. Secondly, health as human capital is an important factor in economic development. Health affects labor supply and the labor productivity of adults, as well as children's school performance. ${ }^{1-3}$ The resources necessary to reach or maintain a certain level of health mainly involve adequate nutrition, sanitation, and preventive and curative health services.

In this paper we implicitly assume the intrinsic importance of health, its importance as a determinant of socio-economic development, that access to health services is one of the important determinants of health and thus that government has an important role to play in ensuring that the population has appropriate access to health services. Strategies will need to consider not only the supply of health services but also demand. In particular, preferences and access barriers faced by different population sub-groups -such as financial, ethnic, and cultural factors-can make accessing health services difficult.

The concept of preference is an imagined "choice" between alternatives and the possibility of rank ordering these alternatives based on the happiness, satisfaction, gratification, or enjoyment they provide. Therefore, preferences and how they are constructed play an important role when deciding whether or not to utilize health care. Together with access, the knowledge of population preferences could be important to designing public policy.

In 2000, the Mexican population (around 97 million) received their health services from a health system composed of three main subsystems: a) a number of social security institutions financed by employers, employees, and the government and providing health insurance to formal sector employees and their families (39.2 million beneficiaries); ${ }^{4}$ ) health services provided by the Ministry of Health and limited services provided by nongovernmental organizations (NGOs) for people without health insurance (an estimated 57.1 million people) ${ }_{i}^{4}$ and c) an extensive private sector, heterogeneous in quality and level of provided services, ${ }^{5}$ which is almost entirely financed by out-of-pocket expenses (only approximately 1 million people have private health insurance). ${ }^{4}$

Such a patchwork of health systems, common in Latin America, complicates the analysis of health system access, coverage, and effectiveness, especially when individuals commonly receive care from multiple sources. Each of the public subsystems collects utilization data but they have almost no information regarding their clients' use of services in other subsystems; in addition, the private sector is atomized into thousands of different independent providers and institutions.

Fortunately, Mexico has a tradition of conducting population-based, nationally-representative health surveys, the most recent of which is the Encuesta Nacional de Salud y Nutrición 2006 (National Health and Nutrition Survey, ENSANUT). The Encuesta Nacional de Salud 2000 (National Health Survey, ENSA-2000) was the most recently available health survey at the time of this analysis, that surveyed 45870 households and 190214 individuals. We used the data from the ENSA-2000 to explore the relationship between individual and household characteristics and utilization of health services when individuals perceived a health problem. What characteristics are associated with not obtaining care from a health professional? What characteristics predict choice of provider/ subsystem among those who seek professional care? Answers to these questions can inform the development of policies and programs to improve access for those who are not receiving care, as well as to reduce the number of low-income families who only have access to low-quality private providers who typically serve the poor.

More specifically, we estimate the degree to which individual variables (characteristics of the specific disease episode, as well as socio-economic and demographic characteristics) and household level variables predict utilization of curative ambulatory services for four types of health providers (self-care, Ministry of Health, social security institutes, and private sector), conditional upon a change in an individual's health status. We decided to focus this analysis on the utilization of curative ambulatory services because of the conditioning that occurs from utilization due to "health care need" (people reporting having had a health problem in the two weeks preceding the survey), which makes the motivation for seeking health care more homogeneous than the motivation to seek preventive health services or hospitalization. When modeling the responses that people have to a health problem, with heterogeneous motivation for seeking health care, it is not possible to avoid the situation in which some variables used as predictors could be correlated with that motivation, and consequently result in incorrect estimates.

There are just two published works in Mexico modeling health care utilization at the national level, Gómez et al. ${ }^{6}$ (1995) and Zamudio (1997). ${ }^{7}$ Both were based on the 1994 National Health Survey; none have been published based on the 2000 National Health Survey. Given that many health programs that potentially have a positive impact on health services utilization were established since 2000, this analysis provides a baseline against which changes from 2000 to 2006 can 
be assessed with the forthcoming 2006 National Health and Nutrition Survey.

\section{Material and Methods}

\section{Data}

Data from the nationally representative ENSA-2000 were used for this study. The ENSA is a rich source of information about household characteristics and service utilization of 190214 individuals living in 45870 households. ${ }^{4}$

In the remainder of the paper, "utilization" refers to "curative ambulatory health care utilization". To estimate the probability of utilization by people who had a "health care need," we restricted the sample to individuals who reported having had a health problem in the two weeks preceding the survey.

Fourteen percent $(27$ 177) of individuals reported having had a health problem in the two weeks before the survey. We excluded anybody who reported having received care from an herbalist or other traditional healer $(0.37 \%$ of the sample). Additional individuals were excluded because of missing data in one or more variables, bringing the sample used for the analysis to 22581 .

The variables used in the analysis are shown in Table I. The provider variable, which is our outcome variable in this study, is a categorical variable that can take four possible values: 0 corresponds to self-care (i.e. not receiving care from a health professional), 1 corresponds to receiving care from the Ministry of Health, 2 to Social Security, and 3 to private providers. In the Ministry of Health services we included services financed by the government and provided by different institutions: (1) Ministry of Health, which has a sliding-scale fee for co-payments which varies from zero for families below the poverty line to the estimated full cost of the service for families in the upper socioeconomic deciles, (2) IMSS Solidaridad, which provides free services to the poorest households entitled to the Oportunidades program aimed at fighting poverty; (3) services from the Sistema para el Desarrollo Integral de la Familia, which is the national program for the comprehensive development of families; (4) National Institute for Indigenous People; (5) the Red Cross; and (6) the National Institutes of Health. In the Social Security institutes we included all the institutions that provide services to employees in the formal sector of the economy. In the Social Security services we included the services provided by different social security institutions for employees in the formal sector of the economy in Mexico: Mexican Institute of Social Security (IMSS), Social Security Institute for Government Workers (ISSSTE), Social Security for Oil Workers
(Pemex), Social Security for Army Forces (SEDENA) and Social Security for Navy Forces (SEMAR).

Based on Andersen's framework of health services utilization $^{8}$ we included individual, household, and community variables to predict utilization of curative ambulatory services. According to this framework, utilization of health services is considered to be a function of three characteristics: (1) predisposing factors, which include education, occupation, ethnicity, social networks, social interactions, culture, attitudes, values, knowledge that people have concerning and towards the health care system, age, and sex; (2) enabling factors, which include personal/family and community characteristics; and (3) need factors which include perceived need.

At the individual level, the variables used as predictors in our model were sex, age, type of health problem in the two weeks preceding the survey, disability, social security beneficiary, private insurance beneficiary, kinship with the head of household, and self-reported severity of the health problem. At the household level the variables used were sex of the head of household, female labor status (head of household or wife), indigenous language of the head of household, and per capita household expenditure. At the community level we used geographical region and municipal poverty level. The remainder of this section is devoted to clarifying the way we constructed and used the variables that are not selfexplanatory in table I, such as type of health problem, geographical zones, per capita household expenditure, age, and municipal poverty level.

Health problems were classified into three categories: acute problems, chronic problems, and injuries. The acute category includes diarrhea, respiratory infections, intestinal parasites, viral infections, and fever without other symptoms. Migraine, diabetes, hypertension, arthritis, asthma, gout, hypercholesterolemia and cholecystitis were categorized as chronic. The injury category consists of intentional or unintentional physical injuries.

Mexico was divided in five geographical zones: The northern zone, the central zone, the metropolitan zone of Mexico City, the southeastern/gulf zone and a zone formed by the PASSPA-states (Programa de Apoyo a los Servicios de Salud para Población Abierta).* While not

\footnotetext{
* The Northern Zone includes the following states: Baja California, Baja California Sur, Coahuila, Chihuahua, Durango, Nuevo León, Sinaloa, Sonora, Tamaulipas and Zacatecas. The Central Zone is formed by Aguascalientes, Colima, Guanajuato, Jalisco, México, Michoacán, Nayarit, Querétaro, San Luis Potosí and Tlaxcala. The Metropolitan Zone of Mexico city only includes the Federal District. The South-Eastern/Gulf Zone is formed by Campeche, Morelos, Puebla, Quintana Roo, Tabasco, Veracruz and Yucatán. The PASSPA Zone is formed by the country's four least developed states: Chiapas, Guerrero, Hidalgo and Oaxaca.
} 
Table I

Descriptive sample statistics for the variables used in the ANAlysis ( $\mathrm{n}=22$ 58I). Mexico, 2007

\begin{tabular}{lc} 
Health care provider & $\%$ \\
\hline Self-care* $^{*}$ & 41.9 \\
\hline Ministry of Health & 21.1 \\
\hline Private sector & 18.8 \\
\hline Social Security & 18.2 \\
\hline & 100.0
\end{tabular}

Sex \%

\begin{tabular}{lr} 
Female & 56.6 \\
\hline Male & 43.4 \\
\hline & 100.0
\end{tabular}

\begin{tabular}{lc} 
Geographical region & $\%$ \\
\hline North & 20.6 \\
\hline Central & 41.8 \\
\hline Metropolitan Zone of Mexico City & 9.4 \\
\hline PASSPA & 10.1 \\
\hline Southeast/gulf & 18.1 \\
\hline
\end{tabular}

\begin{tabular}{cc} 
Disability & $\%$ \\
\hline No disability & 95.9 \\
\hline Any disability & 4.1 \\
\hline & 100.0
\end{tabular}

\begin{tabular}{cc} 
Age (years) & $\%$ \\
\hline $0-4$ & 18.7 \\
\hline $5-20$ & 29.5 \\
\hline $21-59$ & 42.0 \\
\hline $60+$ & 9.8 \\
\hline & 100.0
\end{tabular}

\begin{tabular}{lc} 
Type of health problem & $\%$ \\
\hline Acute & 62.5 \\
\hline Chronic & 8.9 \\
\hline Injury & 3.8 \\
\hline Other ${ }^{\ddagger}$ & 24.8 \\
\hline & 100.0
\end{tabular}

Social security beneficiary

\begin{tabular}{cc}
\hline Nocial security beneficiary & 58.1 \\
\hline Yes & 41.9 \\
\hline & 100.0
\end{tabular}

\begin{tabular}{cc} 
Private insurance beneficiary & $\%$ \\
\hline No & 99.3 \\
\hline Yes & 0.7 \\
\hline & 100.0
\end{tabular}

\begin{tabular}{lc} 
Sex of the head of household & $\%$ \\
\hline Female & 21.8 \\
\hline Male & 78.2 \\
\hline & 100.0
\end{tabular}

\begin{tabular}{lc} 
Kinship with the head of household & $\%$ \\
\hline Head & 24.6 \\
\hline Spouse & 19.6 \\
\hline Child & 46.1 \\
\hline Other & 9.7 \\
\hline & 100.0
\end{tabular}

\begin{tabular}{lc} 
Female labor status (head of household or wife) & $\%$ \\
\hline Does not work & 80.1 \\
\hline Works & 19.9 \\
\hline & 100.0
\end{tabular}

\begin{tabular}{cc} 
Head of household speaks an indigenous language? & $\%$ \\
\hline No & 94.3 \\
\hline Yes & 5.7 \\
\hline & 100.0
\end{tabular}

\begin{tabular}{lc} 
Severity of the health problem & $\%$ \\
\hline Very mild & 2.7 \\
\hline Mild & 49.8 \\
\hline Moderate & 30.4 \\
\hline Severe & 15.8 \\
\hline Very severe & 1.4 \\
\hline & 100.0
\end{tabular}

\begin{tabular}{lc} 
Municipal poverty level & $\%$ \\
\hline Very low & 55.9 \\
\hline Low & 14.4 \\
\hline Moderate & 15.7 \\
\hline High & 10.5 \\
\hline Very high & 3.6 \\
\hline & 100.0
\end{tabular}

Continuous variables $\quad$ Mean SE $\quad$ confidence interval

\begin{tabular}{|c|c|c|c|c|}
\hline Age & 26.2 & 0.21 & 25.8 & 26.6 \\
\hline Years of education for the head of household & 7.3 & 0.09 & 7.2 & 7.5 \\
\hline Per capita expenditure (per trimester) & 3279 & 52.02 & 3177 & 3381 \\
\hline
\end{tabular}

* Includes everybody who did not receive health care and those who received care from a family member, friend, neighbor or pharmacist

‡ Other refers to health problems that were not specified in the survey.

Source: Encuesta Nacional de Salud, 2000 
strictly contiguous, this grouping is the most commonly used in Mexico for sub-national analyses of this type. It is a compromise between geographical proximity and social/cultural/economic similarity.

Household expenditure was used as it is a better measure of permanent income than self-reported income because it is less sensitive to short-term fluctuations, better captures the value of household production, and more accurately reflects unearned income. ${ }^{9}$

Since household expenditure was not captured in the ENSA-2000, household expenditure was imputed using housing characteristics and household assets following Moshiro et al.'s approach. ${ }^{10}$ We used data from the 2000 National Household Income and Expenditure Survey (ENIGH-2000) ${ }^{11}$ to regress the log transformed household expenditure per trimester on: the number of rooms; total number of people living in the household; ownership of a radio, television, VHS player, refrigerator, gas or electric hot water heater, blender, washing machine, telephone, and/or vehicle; presence of running water, a flush toilet, and/or electricity in the house; and finally, the type of floor material and the type fuel used for cooking. The $R^{2}$ for this model was 0.55 , indicating a good fit. The expenditure per trimester was then imputed for the households in the ENSA-2000 using this estimated regression equation and the information available on the same housing characteristics and household assets in our sample.

Previous studies have described a non-linear relationship between health care utilization and age, ${ }^{7-9,12,13}$ and per capita household expenditure.,14,15 For both variables, linear and quadratic model specifications were tested. Both specifications were rejected in favor of a spline specification. ${ }^{16}$ Splines are based on a special class of linear parametric functions and permit much greater flexibility with respect to the specification of the relationship between the dependent and independent variables.

The spline method entails dividing the ranges of variation of an independent variable (age and expenditure, in this case) into $k+1$ discrete regions (with $\mathrm{k}$ being the number of internal thresholds or "knots" in the covariable). In each region, polynomial regression is used to fit the outcome variable. This essentially corresponds to fitting a linear association with utilization but allowing for a different slope in each of the discrete regions of the independent variable, which is reflected in the estimation of $k+1$ separate coefficients. Based on previous findings about the relationship between age and utilization of health services, and based on our bivariate data analysis, the age variable was divided into four categories: 0 to 4, 5 to 20, 21 to 59, and 60+, while quintiles were used for per-capita expenditure.
Municipal poverty level was described using the federal Índice de Marginación, 2000 (Conapo), ${ }^{17}$ a composite measure that includes education levels, housing conditions, income and rurality, and the factors related to living in small villages.**

\section{Estimation strategy}

As in much of the published literature on demand for health services, we employed the Nested Multinomial Logit Model (NMLM), introduced by McFaden, 1981. NMLM relaxes the IAI assumption by allowing correlations across sub-groups of alternatives. This means that NMLM permits the grouping of similar alternatives or alternatives that may be close substitutes.

In Equation 1 we define $V_{i j}$ as a function of $X_{i}$ a vector of variables for individual $i$, which includes the variables presented in Table I as described in the data section, and $\beta_{j,} \gamma_{j}$, and $\varepsilon_{i j}$ parameters to be estimated for provider type $j$, which are assumed to be equal for all individuals.

$V_{i j}=\beta_{j}+X_{i} \gamma_{j}+\varepsilon_{i j}$

According to the outcome variable definition in the data section, $j=0$ corresponds to self-care; $j=1$ receiving care from the Ministry of Health, $\mathrm{j}=2$ from the Social Security, and $\mathrm{j}=3$ from a private provider. Choices 0 and 3 were specified to be independent, whereas 2 and 4 (Ministry of Health and of Social Security) were specified to be correlated. Models with other nesting structures were estimated; we present this model because it resulted in the best fit as measured by the estimated value of the log-likelihood function.

The probability of not using care or using private services is given by:

$$
\mathrm{P}_{\mathrm{ij}}=\frac{e^{\mathrm{V}_{i j}}}{e^{\mathrm{V}_{i 0}+e^{\mathrm{V}_{i 3}}+\left[e^{\bar{\alpha}}+e^{\bar{\alpha}}\right]^{\alpha}}} \quad \text { For } j=0,3
$$

The probability of using Ministry of Health services $(j=1)$ or Social Security $(j=2)$ is given by:

\footnotetext{
** The variables used to construct the poverty level are: illiteracy and percent who have not completed primary school among those 15 years and older, percent living in houses without running water, percent living in houses without sewage, dirt floors, or electricity, percent with an income less than twice the minimum wage and percent residing in localities (towns) with fewer than 5,000 inhabitants. ${ }^{17}$
} 


$$
\mathrm{P}_{\mathrm{ij}}=\frac{\frac{\mathrm{v}_{i j} \mathrm{~V}_{i 1} \mathrm{v}_{i 2}}{\left(e^{\alpha}\right)\left[e^{\alpha}+e^{\bar{\alpha}}\right]^{\alpha}}}{e^{\mathrm{V}_{i 0}}+e \mathrm{v}^{i 3}+\left[e^{\frac{i 1}{\alpha}}+e^{\left.\frac{\mathrm{V}_{2}}{\alpha}\right]^{\alpha}}\right.} \quad \text { For } j=1,2
$$

The parameter $\alpha$ is a measure of the degree of association between alternatives and thus only relevant when the alternatives are not independent (1 and 2). $\alpha=1$ corresponds to the complete independence and thus to the simple multinomial logist model. $\alpha=0$ would imply that individuals consider the nested alternatives (services of the Ministry of Health and Social Security) as being perfect substitutes.

The corresponding log-likelihood function is:

$\ln \mathrm{L}_{\mathrm{i}}=\sum_{j=0}^{3} D_{i j} \ln P_{i j}$

Where $D_{i j}$ is a dichotomous variable taking the value of 1 if individual $i$ chooses alternative $j$.

The NMLM was estimated using the maximum likelihood method for Equation 5 with STATA 8.2. Self-care was chosen as the reference category for the dependent variable.

\section{Results}

The sample characteristics are shown in Table I. Table II shows the estimated results of the model and their significance. The estimated value for $\alpha$ is 0.7 and is statistically different from both zero and one, thus rejecting the MLM specification in favor of NMLM. The estimated value for $\alpha$ indicates that the Ministry of Health and Social Security health services are to some extent substitutable.

The magnitude of the coefficients presented in II cannot be easily interpreted in terms of probabilities, although, when significant, the signs of the coefficients indicate the direction of the effect in comparison to the reference category. To facilitate the presentation and interpretation of the results, the coefficients were transformed into marginal effects (e.g. the \% change in the dependent variable for $1 \%$ change in the independent variable from the mean value of the independent variable) and are presented in table III. All marginal effects for the continuous variables were calculated at the variable mean. For categorical variables the marginal effect is the change in the dependent variable as a consequence of moving from the reference category to the category in question.

Ambulatory health care was used less frequently by children from 0 to 4 years of age. A similar effect, albeit smaller, was found for 5 to 20 year-olds. The coefficients for Social Security and private providers changed sign for 21 to 59 year-olds, indicating that the probability of utilizing these services increases with age. Thus, the highest probabilities for health care utilization were found among the youngest and oldest individuals. (Tables II and III.)

The utilization of Ministry of Health and Social Security services increased (but at a diminishing rate) with higher education levels for the head of household. Private health care utilization increased with education as well but at an increasing rate.

Sex was only significantly associated with the use of Ministry of Health services, with women more likely to use these services. Male-headed households were more likely to seek care, but this was only significant for private providers. The presence of a working woman (irrespective of whether she was head of the household or married to the head) reduced the probability of health care utilization. Disabled individuals were less likely to utilize any type of health care, but this was also only significant for private providers. The likelihood of utilization was lower for the head of household than for his children or spouse. Type of health problem was significantly correlated with utilization: the probability being lower across all alternatives for acute problems than for other types.

The probability of using Ministry of Health and the Social Security services was higher when the head of household spoke an indigenous language. The opposite was true for private health care, even though the effect was small and not statistically significant (tables II and III).

Being a Social Security beneficiary was, as expected, strongly positively associated with utilization of Social Security services (1299\%) and strongly negatively associated with self care $(28 \%)$. It was also negatively associated with utilizing private providers and the Ministry of Health, even though the latter did not reach statistical significance. Having private health insurance was positively associated with using both private health care and Social Security and negatively associated with self-care.

The differences between the northern region and the others were only significant for Social Security and private services. The probability of using Social Security services was higher in the northern region, controlling for beneficiary status, whereas the probability of using private services was higher in the other regions, except for the Mexico City metropolitan area.

As one would expect, health care utilization increased with increasing perceived severity of the health problem, except for private health care services where the opposite association was seen when going from a serious to a very serious health problem. Although this 
Table II

Estimation of the NMLM for choice of health CARE PRovider*. Mexico, 2007

\begin{tabular}{|c|c|c|c|}
\hline $\begin{array}{l}\text { Log likelihood = -24550.879 } \\
\alpha=0.700+++\end{array}$ & Ministry of Health & Social Security & $\begin{aligned} & \text { Number of observations }=2258 I \\
& \text { Wald } \mathrm{chi}^{2}(36)=1195.2 \\
& \text { Prob }>\text { chi }^{2}=0.0000 \\
& \text { Private }\end{aligned}$ \\
\hline Constant & 0.064 & $-3.452^{\#}$ & $-3.647^{\#}$ \\
\hline \multicolumn{4}{|l|}{ Age $^{\ddagger}$ (months) } \\
\hline $0-4$ & $-0.148^{\#}$ & $-0.133^{\#}$ & $-0.179^{\#}$ \\
\hline $5-20$ & $-0.048^{\#}$ & $-0.027^{\#}$ & $-0.04^{\#}$ \\
\hline $21-59$ & 0.000 & $0.012^{\#}$ & $0.006^{\&}$ \\
\hline $60-$ & $0.011^{\neq}$ & 0.005 & 0.003 \\
\hline Years of education for the head of household & $0.032^{\&}$ & $0.065^{\#}$ & 0.006 \\
\hline Years of education for the head of household squared & $-0.002^{\&}$ & $-0.003^{\#}$ & $0.002^{\#}$ \\
\hline Sex (female as reference) & $-0.13^{\#}$ & 0.000 & 0.013 \\
\hline Sex of the head of household (female as reference) & 0.006 & 0.083 & $0.108^{\&}$ \\
\hline Spouse of head of household works & $-0.139^{\#}$ & -0.028 & $-0.089^{\neq}$ \\
\hline Disabled & -0.114 & -0.003 & $-0.203^{\neq}$ \\
\hline Head of household speaks an indigenous language & $0.43^{\#}$ & $0.251^{\&}$ & 0.133 \\
\hline Social security beneficiary & -0.148 & $2.403^{\#}$ & $-0.429^{\#}$ \\
\hline Private insurance beneficiary & -0.259 & $1.15 I^{\#}$ & $0.93^{\#}$ \\
\hline \multicolumn{4}{|l|}{ Type of health problem (reference group: acute) } \\
\hline Chronic & $0.513^{\#}$ & $0.616^{\#}$ & $0.46 I^{\#}$ \\
\hline Injury & $0.539^{\#}$ & $0.659^{\#}$ & 0.114 \\
\hline Other $^{\infty}$ & $0.596^{\#}$ & $0.698^{\#}$ & $0.759^{\#}$ \\
\hline \multicolumn{4}{|l|}{ Geographic region (reference group: north) } \\
\hline Centre & $-0.098^{\&}$ & $-0.24 \iota^{\#}$ & 0.065 \\
\hline Metropolitan zone of Mexico City & -0.031 & $-0.632^{\#}$ & $-0.224^{2}$ \\
\hline PASSPA & -0.074 & $-0.236^{\#}$ & $0.196^{\&}$ \\
\hline Southeast/gulf & -0.054 & -0.083 & $0.181^{\#}$ \\
\hline \multicolumn{4}{|l|}{ Kinship with the head of household (reference group: Head) } \\
\hline Spouse & $0.287^{\#}$ & $0.235^{\#}$ & $0.27 I^{\#}$ \\
\hline Child & -0.002 & $0.215^{\#}$ & $0.167^{\&}$ \\
\hline Other & $0.204^{\&}$ & $0.373^{\#}$ & $0.312^{\#}$ \\
\hline \multicolumn{4}{|l|}{ Severity of the health problem (reference group: very mild) } \\
\hline Mild & $0.366^{\#}$ & $0.506^{\#}$ & $0.294^{\&}$ \\
\hline Moderate & $0.567^{\#}$ & $0.7 I I^{\#}$ & $0.536^{\#}$ \\
\hline Severe & $1.294^{\#}$ & $1.442^{\#}$ & $1.525^{\#}$ \\
\hline Very severe & $1.55 \mathrm{I}^{\#}$ & $1.787^{\#}$ & $1.389^{\#}$ \\
\hline \multicolumn{4}{|l|}{ Municipal poverty level (reference group: very low) } \\
\hline Low & $0.287^{\#}$ & 0.026 & -0.06 \\
\hline Moderate & $0.215^{\#}$ & -0.063 & $0.178^{\#}$ \\
\hline High & $0.378^{\#}$ & $-0.242^{\&}$ & 0.119 \\
\hline Very high & $0.3++$ & $-0.565^{\&}$ & $-0.61 I^{\#}$ \\
\hline
\end{tabular}

Per capita expenditure quintiles $\$, \$$

\begin{tabular}{|c|c|c|c|}
\hline First & $-0.314^{\#}$ & $0.367^{\neq}$ & $1.442^{\#}$ \\
\hline Second & $-0.156^{\neq}$ & $0.212^{\neq}$ & $0.62 I^{\#}$ \\
\hline Third & 0.084 & $0.166^{\&}$ & $0.443^{\#}$ \\
\hline Fourth & $-0.078^{\neq}$ & $-0.072^{\neq}$ & $0.285^{\#}$ \\
\hline Fifth & $-0.058^{\&}$ & -0.025 & 0.023 \\
\hline
\end{tabular}

NMLM= Nested Multinomial Logit Model
* Reference category is self care
₹ Variable transformed in a spline for the estimation
$\S$ Variable divided by 1000 for the estimation
$\& p<0.05$
$\neq p<0.10$
\# $\mathrm{p}<0.01$
${ }^{\infty}$ Other refers to health problems that were not specified in the survey 
Table III

Marginal effects for the four alternatives. Mexico, 2007

Self-care

Ministry of Health

Social security

Private

Age* (months)

\begin{tabular}{|c|c|c|c|c|}
\hline $0-4$ & 11.90 & -3.61 & -1.66 & -6.43 \\
\hline $5-20$ & 2.40 & -2.61 & 0.22 & -1.58 \\
\hline $21-59$ & -0.28 & -0.48 & 1.16 & 0.34 \\
\hline $60+$ & -0.34 & 0.85 & 0.01 & -0.03 \\
\hline
\end{tabular}

\begin{tabular}{|c|c|c|c|c|}
\hline Years of education of the head of household* & -1.27 & -1.13 & 1.92 & 3.00 \\
\hline Sex (female as reference) $)^{\ddagger}$ & 2.30 & $-12.0 \mid$ & 5.61 & 3.68 \\
\hline Sex of the head of household (female as reference) $)^{\ddagger}$ & -3.18 & $-3.7 \mid$ & 7.21 & 7.89 \\
\hline Spouse of head of household works ${ }^{\ddagger}$ & 4.84 & -10.36 & 4.73 & -4.09 \\
\hline Disabled $\ddagger$ & 6.13 & -7.02 & 8.71 & -13.37 \\
\hline Head of household speaks an indigenous language $\dagger$ & -14.36 & 35.21 & 5.02 & -2.23 \\
\hline Social security beneficiary $\ddagger$ & -28.25 & -61.68 & 1299.86 & -53.26 \\
\hline Private insurance beneficiary $\ddagger$ & -36.50 & -65.76 & 149.89 & 60.86 \\
\hline \multicolumn{5}{|l|}{ Type of health problem } \\
\hline Chronic & -23.77 & 25.22 & 44.79 & 20.87 \\
\hline Injury & -19.89 & 34.72 & 59.49 & -10.23 \\
\hline Other & -31.03 & 23.18 & 42.22 & 47.37 \\
\hline
\end{tabular}

Geographic region

\begin{tabular}{lrrrr} 
Central & 3.93 & $-3.5 I$ & -21.20 & \multicolumn{1}{c}{10.95} \\
\hline Metropolitan Zone of Mexico City & $I I .89$ & $I 7.52$ & -49.65 & -10.54 \\
\hline PASSPA & 0.59 & -4.07 & -23.67 & -9.82
\end{tabular}

Kinship with the head of household $\ddagger$

\begin{tabular}{|c|c|c|c|c|}
\hline Spouse & -13.08 & 16.74 & 8.39 & 13.99 \\
\hline Child & -5.60 & -8.99 & 23.54 & 11.60 \\
\hline Other & $-|3.8|$ & 2.85 & 30.67 & 17.76 \\
\hline
\end{tabular}

Severity of the health problem ${ }^{\ddagger}$

\begin{tabular}{lrrrr} 
Mild & -14.14 & 21.27 & 47.78 & 15.21 \\
\hline Moderate & -22.67 & 33.43 & 63.39 & 12.12 \\
\hline Severe & -53.54 & 65.79 & 104.14 & 13.43 \\
\hline Very Severe & -57.64 & 92.56 & 168.66 & 69.95
\end{tabular}

Municipal poverty level ${ }^{\ddagger}$

\begin{tabular}{|c|c|c|c|c|}
\hline Low & $-4.7 \mid$ & 32.68 & -8.16 & -10.23 \\
\hline Moderate & -6.68 & 21.18 & -18.04 & 11.47 \\
\hline High & -7.27 & 48.11 & -38.24 & 4.47 \\
\hline Very high & 9.05 & 64.78 & -51.33 & -40.83 \\
\hline
\end{tabular}

Per capita expenditure quintiles

\begin{tabular}{|c|c|c|c|c|}
\hline First & 0.02 & -0.23 & 0.43 & 1.02 \\
\hline Second & -0.10 & -0.45 & 0.45 & 0.98 \\
\hline Third & -0.28 & -0.10 & 0.20 & 0.87 \\
\hline Fourth & -0.18 & -0.49 & -0.46 & 0.95 \\
\hline Fifth & 0.03 & -0.39 & -0.09 & 0.18 \\
\hline
\end{tabular}

* Percent change in probability for a change of unit in the independent variable

¥ Percent difference in probability with respect to the omitted category (category of reference in the model)

$\S$ Percent change in probability for a $1 \%$ change in the independent variable 
might appear counterintuitive, it is consistent with local conventional wisdom because households with very serious health problems anticipate private expenditures that may exhaust their ability to pay and thus seek public services. The probability of self-care decreased rapidly with increasing perceived severity (tables II and III).

Utilization of Social Security services was inversely associated with poverty level, even adjusting for beneficiary status. The opposite was seen for the Ministry of Health. Additionally, private health care utilization increased rapidly with decreasing poverty level (tables II and III).

Simulations were used to explore the associations between variations in household socio-economic status (SES) and the utilization of different types of health

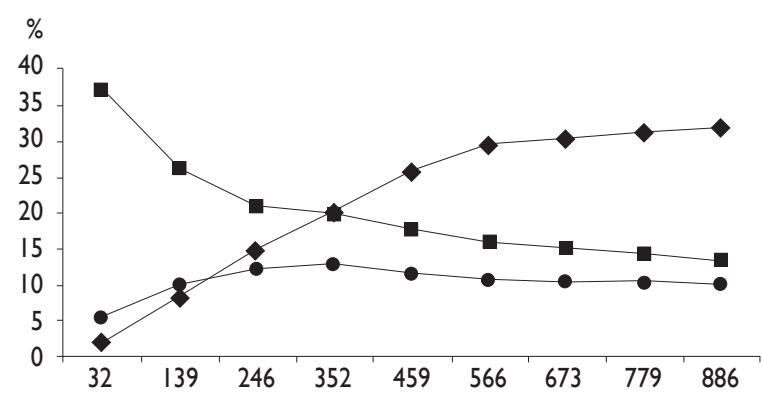

Per capita household expenditure in dollars of 2000 (per trimester)

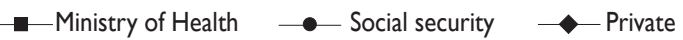

Figure I. Probability of using health Care services by EXPENDITURE LEVEL

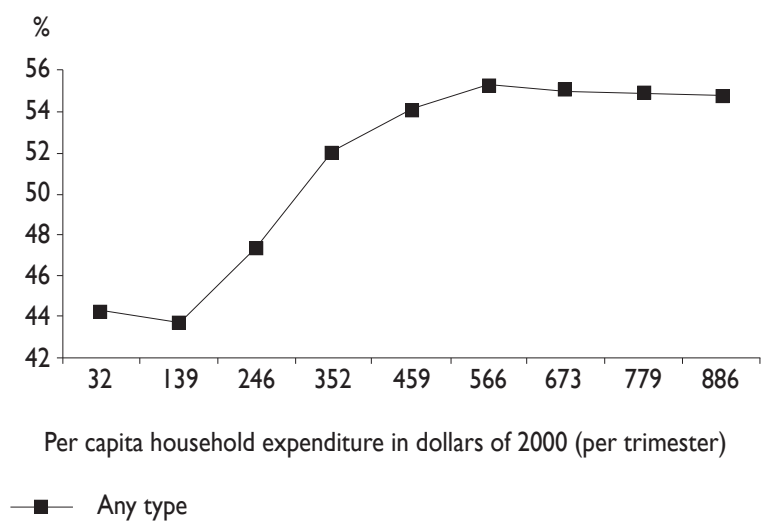

Figure 2. Probability of using health care services by EXPENDITURE LEVEL

salud pública de méxico / vol. 50, no. 5, septiembre-octubre de 2008 services. The probability of using each type of health care was estimated using the coefficients obtained in the NMLM and equations 2 and 3. We let household expenditure vary from the $5^{\text {th }}$ to the $95^{\text {th }}$ percentile distribution, while all other variables were set to the sample mean. The results of this exercise are shown in figures 1 and 2.

Increasing household expenditures (i.e. higher SES) was associated with decreasing probability of using Ministry of Health services with the negative slope being steeper among poorer households. On the other hand, as SES increased, the probability of using Social Security increased initially and leveled off early, from around US\$ 352, while for private services the initial increase was more pronounced and continued to about US\$ 779 before plateauing (figure 1).

Figure 2 shows the sum of the curves in figure 1, i.e. the probability of using any type of health care (the complement is the probability of self-care). The graph suggests that utilization by the poorest and wealthiest households was relatively unresponsive to changes in SES, with the probability of utilizing professional services increased rapidly from about US\$ 139 to US\$ 566.

\section{Discussion}

The association between the economic status of the household and the utilization of formal health care is consistent with the findings of other studies conducted in Mexico, ${ }^{7}$ Finland, ${ }^{18}$ Mali, ${ }^{19}$ and the United States. ${ }^{20}$ However, controlling for beneficiary status and for the other covariates reveals differential effects for the different alternatives. The strongest increase in utilization with increasing levels of household expenditure was found for private services, followed by Social Security services. Utilization of Ministry of Health services was negatively associated with household expenditure. This suggests that with increasing economic status, utilization of Ministry services is replaced by private and Social Security services, implying that the former are considered an inferior good. Interestingly, increasing levels of municipal SES have similar effects upon the behavior of households in the municipality, even when correcting for household SES. This could be a social norm effect (the same household, living in a wealthier community, is likely to imitate the utilization behavior of its neighbors) but more likely reflects the correlation of supply of health services (quantity, choice, and quality) with municipal poverty level.

These findings provide valuable information about individual preferences, which have important consequences for the health care system and the reforms that are currently being implemented. Even though 
health care services through the Ministry of Health are less costly than private services and two recent studies suggest that private services for the poor are of lower technical quality than those in the public sector (S. Barber, personal communication based on preliminary data analysis), our findings show that with increasing economic status, individuals replace the former by the latter. This effect is strongest among poorer families for whom the sacrifice of not consuming other goods in order to pay for private health services is the largest. This suggests that individuals may perceive the services of the Ministry of Health as significantly lower in quality or convenience.

Not using health services (self-care) in case of a change in individual health status is largely explained by the lack of beneficiary status either with a social security institute or with private insurance. The poor are the least likely to be beneficiaries and the most likely to experience catastrophic health expenditures (as a proportion of income). ${ }^{4}$ This finding, together with the results discussed in the previous paragraph, suggests that expansion of health insurance coverage, as currently being undertaken by the Mexican government, may significantly reduce health inequalities that are due to a lack of seeking medical attention.

We found that after controlling for economic status, education, municipal poverty level, and beneficiary status, indigenous people use health care services more frequently in response to a perceived alteration in their health status. This result contradicts conventional wisdom and the findings of other studies. We hypothesize that the negative association between health care utilization and belonging to an indigenous group found in bivariate analyses is actually due to the association between health care utilization and poverty, urbanization, low educational level, and lack of beneficiary status with the social security institutes, rather than to the mere fact of being indigenous.

In conclusion, this finding implicitly suggests that programs or policies that seek to promote curative ambulatory health care service utilization should use poverty, educational level, locality size, and beneficiary status for targeting rather than ethnicity. However, an alternative explanation for the difference may lie in differential perception of illness episodes between indigenous and non-indigenous peoples, given that our analysis examined utilization in response to a recent self-reported illness episode and most previous analyses have examined overall utilization.

In addition, our findings could be useful for the design and evaluation of new programs and for public policy. The 2006 National Health Survey will enable analysis of the simultaneous effect on propensity to utilize health services through the various programs that have been started since 2000. These programs include (1) the National Crusade for Health Care Quality, which aims to improve the quality of care, the responsiveness of providers, and the negative image with regard to quality of care in Ministry of Health facilities, (2) the Seguro Popular health insurance program for the uninsured population which aims to provide limited prepaid insurance to those without access to Social Security facilities, and (3) the expansion of the Oportunidades health/nutrition/education anti-poverty program to urban areas, which is expected to increase utilization of Ministry of Health services by the poorest quintile of the population.

The largest limitation of our study is the omission from the model of variables capturing the characteristics and attributes of the alternative types of health care such as availability, distance, cost, and quality, because these variables are not available within the ENSA-2000 and the location data for the households is not sufficiently detailed to enable reconstruction of distances to the relevant alternatives. The absence of these data could generate biased estimates if variation in supply-side variables is correlated with the independent variables in the model. To minimize such biases we included the municipal poverty level generated by Conapo ${ }^{17}$ and the geographic region in our model because previous studies have shown that these two variables explain a significant proportion of the municipal-level variation in supply and characteristics of health services. ${ }^{21,22}$

\section{References}

I.Anil BD. Nutrition and Labor Productivity in Agriculture: Estimates for Rural South India. Rev Ec and Stat 1988;70(3):406-4I3.

2. Behrman JR, Anil BD. Health and Nutrition. In: Hollis BC, Srinivasan, ed. Handbook of Development Economics Vol. I.Amsterdam: North-Holland, |988:63|-7||.

3. Strauss J. Does Better Nutrition Raise Farm Productivity? Journal of Political Economy 1986;94:297-320.

4.Valdespino JL, Olaiz G, López-Barajas MP, Mendoza L, Palma O,Velázquez O, et al. Encuesta Nacional de Salud 2000, Tomo I:Vivienda, población y utilización de servicios de salud. Cuernavaca, México: Instituto Nacional de Salud Pública, 2003.

5. Barraza-Lloréns M, Bertozzi S, González-Pier E, Gutiérrez JP.Addressing inequity in health and health care in Mexico. Health Aff 2002;2I (3):47-56. 6. Gómez de León J, Bloom E, Bitran R, Dow W, Straffon B, Orozco M. La demanda de servicios de salud en México: Un análisis econométrico. México: Conapo, 1995.

7. Zamudio A. La demanda por servicios médicos en México. México DF: Centro de Investigación y Docencia Económicas, AC. Documento de Trabajo Número 94, 1997.

8. Andersen RM. Revisiting the behavioral model and access to medical care: does it matter? J Health Soc Behav 1995;36: I- 10. 
9. Gertler P, van-der-Gaag J.The Willingness to pay for medical care: evidence from two developing countries. Baltimore: Johns Hopkins Press, 1990.

10. Moshiro C, Heuch I, Nordrehaug-Astrom A, Stel P, Hemed Y,

Kuale G. Injury morbidity in an urban and a rural area in Tanzania: an epidemiological survey. BMC Public Health 2005;5: I .

II. Instituto Nacional de Estadística, Geografía e Informática. Encuesta Nacional de Ingreso y Gasto de los Hogares, 2000. Mexico: Instituto Nacional de Estadística, Geografía e Informática, 200I.

12. Masako I.The demand for medical care: evidence from urban areas in Bolivia. Washington, D.C:The World Bank. Living Standards Measurement Study Working Paper Number 123, 1996.

13. Sahh DE, Younger SD, Genicot G. The demand for health care services in rural Tanzania. Oxf Bull Econ Stat 2003;65(2):24I-260.

I4.Aking JS, Guilkey DK, Denton EH. Quality of services and demand for health care in Nigeria:A multinomial probit estimation. Soc Sci Med 1995;40(II):1527-1537.

15.Wong EL, Popkin MB, Guilkey DK, Akin JS.Accessibility, quality of care and prenatal care use in the Philippines. Soc Sci Med 1987;24(II):927-944. 16. Greene,W.Análisis Econométrico. $3^{\mathrm{a}}$ edición. Madrid: Prentice Hall, 1999. 17. Consejo Nacional de Población. Índice de marginación, 2000. Mexico: Consejo Nacional de Población, 200I.

18. Häkkinen U. Change in determinants of use of physician services in Finland between 1987 and 1996. Soc Sci Med 2002;55(9):1523-1537.

19. Mamadou M. Quality of care and the demand for health services in Bamako, Mali: the specific roles of structural, process, and outcome components. Soc Sci Med 2003;56(6): I I 83-I I 96.

20. Meer J, Rosen HS. Insurance and the utilization of medical services. Soc Sci Med 2004;58(9): 1623-1632.

2I. OCDE. Estudios de la OCDE sobre los sistemas de salud: México. Mexico City: OCDE/SSA, 2005

22. van Doorslaer E, Masseria C, OECD Health Equity Research Group Members. Income-Related Inequality in the Use of Medical Care in 2I OECD Countries. In: OECD (ed). Towards High-Performing Health Systems. Paris: OECD Health Policy Studies, 2004. 